\title{
In vitro release of two anti-muscarinic drugs from soft contact lenses
}

This article was published in the following Dove Press journal:

Clinical Ophthalmology

14 September 2017

Number of times this article has been viewed

\author{
Alex Hui' \\ Magdalena Bajgrowicz- \\ Cieslak $^{2}$ \\ Chau-Minh Phan ${ }^{3}$ \\ Lyndon Jones ${ }^{3}$
}

'School of Optometry and Vision Science, UNSW Sydney, Sydney, NSW, Australia; ${ }^{2}$ Department of Mechanics, Material Science and Engineering, Wroclaw University of Technology, Wroclaw, Poland; ${ }^{3}$ Centre for Contact Lens Research, School of Optometry \& Vision Science, University of Waterloo, Waterloo, ON, Canada
Correspondence: Alex Hui

School of Optometry and Vision

Science, UNSW Sydney, Sydney 2052.

NSW, Australia

Tel +6I 293859879

Email alex.hui@unsw.edu.au
Abstract: The purpose of this study was to investigate the release of the anti-myopia drugs atropine sulfate and pirenzepine dihydrochloride from commercially available soft contact lenses. Standard ultraviolet (UV) absorbance-concentration curves were generated for atropine and pirenzepine. Ten commercially available contact lenses, including four multifocal lenses, were loaded by soaking in atropine or pirenzepine solutions at two different concentrations $(10 \mathrm{mg} / \mathrm{mL}$ and $1 \mathrm{mg} / \mathrm{mL}$ ). The release of the drugs into phosphate-buffered saline was determined over the course of 24 hours at $34^{\circ} \mathrm{C}$ using UV absorbance. Materials with surface charge released the greatest amount of atropine when loaded with either concentration when compared to the other lens types $(p<0.05)$, releasing upward of $1.026 \pm 0.035 \mathrm{mg} / \mathrm{lens}$ and $0.979 \pm 0.024 \mathrm{mg} / \mathrm{lens}$ from etafilcon A and ocufilcon A, respectively. There were no significant differences in the amount of atropine or pirenzepine released from the multifocal and non-multifocal lenses made from the same lens materials. Narafilcon A material demonstrated prolonged release of up to 8 hours when loaded with pirenzepine, although the overall dose delivered from the lens into the solution was among the lowest of the materials investigated. The rest of the lenses reached a plateau within 2 hours of release, suggesting that they were unable to sustain drug release into the solution for long periods of time. Given that no single method of myopia control has yet shown itself to be completely effective in preventing myopia progression, a combination of optical and pharmaceutical devices comprising a drug delivering contact lens presents a novel solution that warrants further investigation.

Keywords: contact lens, drug delivery, myopia control, atropine, pirenzepine, multifocal

\section{Introduction}

With prevalence in excess of $80 \%$ in the young adult population reported in areas of China, Singapore, Taiwan and South Korea, ${ }^{1-4}$ myopia is fast approaching epidemic proportions in the region and represents an emerging health concern. ${ }^{5-7}$ The morbidity of myopia, where light rays focus in front of the retina leading to blurred distance vision, ranges from simple quality of life issues associated with refractive correction to more serious complications such as risk of developing glaucoma, retinal detachment and maculopathy. ${ }^{8,9}$ While a complete understanding of the pathogenesis of myopia development remains elusive, researchers continue to actively investigate methodologies to slow and prevent myopia development through the use of optical and pharmaceutical treatments. Optical treatment strategies to reduce myopia center on inducing favorable light optics such as with center distance/peripheral near multifocal soft contact lenses. ${ }^{10}$ Studies utilizing primarily optical means of slowing myopia have demonstrated a reduction in myopic progression by upward of $45 \%{ }^{11}$

Pharmaceuticals to prevent myopia progression have focused almost exclusively on the anti-muscarinic agents atropine sulfate and pirenzepine dihydrochloride. ${ }^{12}$ 
The mechanism of action of these agents in preventing myopia progression is unknown, but investigators have speculated on the impact of these drugs on the sclera, choroid or retina, all of which contain muscarinic receptors. ${ }^{13}$ Several large-scale, randomized, controlled studies have demonstrated the benefits of atropine as a means of effective myopia control. The Atropine Treatment of Myopia Trials (ATOM1 and ATOM2) run in Singapore have demonstrated significant success in slowing myopia progression with the use of $1 \%, 0.5 \%, 0.1 \%$ and even $0.01 \%$ solutions of atropine instilled nightly into the eyes of myopic children compared to placebos. ${ }^{13,14}$ The effectiveness of $0.01 \%$ atropine in myopia control is of particular note as the adverse side effects of atropine, namely, prolonged decrease in accommodative amplitude and increased light sensitivity, are all but eliminated through the use of such a low concentration. ${ }^{14}$ It has been suggested that a dosage concentration of no more than $0.02 \%$ atropine is needed to prevent adverse clinical signs or symptoms. ${ }^{15}$ Atropine at such low concentrations is currently not available commercially and thus must be compounded prior to dispensing. There remains some concern as to the duration and longevity of the treatment, as the initial ATOM1 and ATOM2 trials were limited to only 2 years of treatment, followed by 1 year of observation. It has been suggested that $50 \%$ of myopia progression may be reduced through use of $0.01 \%$ atropine eye drops in the appropriate population. ${ }^{16}$

The use of a selective M1 muscarinic antagonist, pirenzepine dihydrochloride, to manage myopia has also been investigated. ${ }^{17}$ In contrast to atropine, the agent has little or no effect on accommodation or pupil size and has been shown to be relatively safe and well tolerated in study populations. ${ }^{17}$ The effect of the drug in slowing myopia progression is thought to be $<1 \%$ atropine, with study participants progressing on average $0.47 \mathrm{D}$ after a year on twice a day instillation of $2 \%$ pirenzepine gel when compared to 0.84 D for placebo controls. ${ }^{18-20}$ Pirenzepine eye drops are currently not commercially available. ${ }^{8}$

Although there has been success with both pharmacological and optical means of myopia control, no intervention has yet demonstrated complete prevention of myopia progression. One of the limitations of eye drops is poor ocular residence time and penetration, which is commonly overcome through the use of increased drug concentrations or drop instillation frequency. ${ }^{21}$ However, for myopia control purposes, increases in concentration are particularly undesirable when using atropine, due to the side effects that impact visual function. Alternatively, the use of an extended drug release system, such as a drug-releasing contact lens, may be able to modulate the dosage rate so that adverse effects may be mitigated. ${ }^{21}$ Contact lenses as a means of drug delivery has been suggested since the late 1960s and was even included in the original hydrogel patent of Wichterle and Lim. ${ }^{22,23}$ Combining the need for refractive correction with delivery of pharmaceuticals may also have an effect on improving patient compliance, which sees a 50\% medication discontinuation rate during management of chronic eye diseases such as glaucoma. ${ }^{24}$ The use of contact lenses in children has also been shown to have a positive impact on children's self-perceptions regarding physical appearance, athletic competence, social acceptance and overall quality of life. ${ }^{25,26}$ The use of multifocal contact lens designs in such a drug delivery application would be most interesting, as such lens designs could combine pharmaceutical and optical methods to manage myopia and thus hold potential to demonstrate an additive or synergistic effect on myopia control.

Unmodified, commercially available contact lenses have previously been investigated in vitro for their uptake and release properties of ocular drugs to combat bacterial and fungal infections, ${ }^{27,28}$ postoperative pain, ${ }^{29}$ inflammation ${ }^{30}$ and allergies. ${ }^{31}$ In the majority of cases, drug release from commercial lenses in vitro is characterized by a rapid release to a concentration plateau, limiting their use for long-term drug delivery. ${ }^{27-31}$ The goal of the current study was to investigate the release of the anti-myopia drugs atropine sulfate and pirenzepine dihydrochloride from ten different commercially available soft contact lenses in vitro. The effect of drug type, lens material and loading concentration on the overall amount of drug released and the kinetics of release over time and the impact of using the multifocal design from lenses formed from the same material were investigated.

\section{Methods}

\section{Reagents and materials}

Atropine sulphate, pirenzepine dihydrochloride and $10 \times$ phosphate-buffered saline (PBS) were purchased from Sigma-Aldrich Co. (Oakville, ON, Canada). UV-Star 96-well microplates, from Greiner Bio-One, and lens paper were purchased from VWR (Mississauga, ON, Canada). All reagents and materials were used as received.

\section{Contact lenses}

Eight different base materials forming ten commercially available contact lenses were used in this study: etafilcon A (1-Day Acuvue Moist) and narafilcon A (1-Day Acuvue TruEye) from Johnson \& Johnson (Jacksonville, FL, USA); ocufilcon B (Biomedics 1 Day), omafilcon A (Proclear 
1 Day and Proclear 1 Day Multifocal), omafilcon B (Proclear Multifocal) and comfilcon A (Biofinity Multifocal) from CooperVision (Pleasanton, CA, USA); and delefilcon A (Dailies Total One) and nelfilcon A (Focus Dailies and Focus Dailies Progressive) from Alcon Laboratories, Inc. (Fort Worth, TX, USA). All contact lenses were purchased commercially and had a dioptric power of $-3.00 \mathrm{D}$. For the comfilcon A and omafilcon B lenses, a +2.50 D add with center distance-near surround design ("D" Lens) was selected. The abbreviations "SV" and "MF" are utilized to denote the single vision and multifocal variant of a particular lens material being discussed. Detailed properties of the lenses selected are presented in Table 1.

\section{Atropine and pirenzepine standard curves}

In all, $1 \%(10 \mathrm{mg} / \mathrm{mL})$ and $0.1 \%(1 \mathrm{mg} / \mathrm{mL})$ atropine and pirenzepine solutions were created by dissolving the drugs in PBS. The absorption spectra were determined by conducting a wavelength absorption scan of $100 \mu \mathrm{L}$ of the drug solutions in a UV-Star 96-Well Greiner Bio-One microplate using a plate reader (M5 Microplate Reader; Molecular Devices LLC, Sunnyvale, CA, USA). Absorption-concentration standard curves were generated by varying the concentration of the drugs from 0.001 to $1 \mathrm{mg} / \mathrm{mL}$ and reading the absorbance at wavelengths of $280 \mathrm{~nm}$ for pirenzepine and $220 \mathrm{~nm}$ for atropine. The linear range for both drugs was between 0.0 and $0.5 \mathrm{mg} / \mathrm{mL}$.

\section{Release of atropine and pirenzepine from contact lenses}

Four lenses of each lens type were removed from the blister packs and dried briefly on lens paper before being placed into $2 \mathrm{~mL}$ of the drug solution (atropine or pirenzepine, $10 \mathrm{mg} / \mathrm{mL}$ or $1 \mathrm{mg} / \mathrm{mL}$ concentration) for 24 hours. Loaded lenses were removed from the drug solutions and briefly dried on lens paper to remove any surface solution. The lenses were then placed into $4 \mathrm{~mL}$ of PBS in a glass vial in a $34^{\circ} \mathrm{C}$ shaking water bath. In all, $100 \mu \mathrm{L}$ of the release solution was periodically sampled and the concentration was determined using ultraviolet (UV) absorbance over the course of 24 hours. Samples were diluted in PBS if necessary, such that readings were within the linear range of the standard curves.

\section{Data analysis}

Analysis of release curves was undertaken using a repeated measures analysis of variance (ANOVA), with the lens type as a categorical factor. Post hoc Tukey's tests were performed as needed, and comparisons of the concentrations reached over time for each lens type were used to determine if drug release had reached a plateau. A $p$-value of $<0.05$ was considered to be statistically significant. All statistics were performed using Statistica version 7.1 (StatSoft, Inc., Tulsa, OK, USA).

\section{Results}

A summary of the amount of atropine and pirenzepine released into the releasing solutions from the different lens materials after 24 hours is presented in Table 2.

\section{Release of atropine from contact lenses - $10 \mathrm{mg} / \mathrm{mL}$ loaded}

The release of atropine over time from the different contact lens materials after loading with $10 \mathrm{mg} / \mathrm{mL}$ atropine solutions for 24 hours is presented in Figure 1. There were statistically significant differences in the amount of atropine released over time between the different lens materials $\left(F_{126,420}=25.953\right.$, $p<0.0001$ ). Post hoc analysis suggested that the atropine released over time from narafilcon $\mathrm{A}$, nelfilcon $\mathrm{A}$ (SV and $\mathrm{MF}$ ), delefilcon A and comfilcon A (MF) was all statistically similar to each other ( $p>0.05$, Tukey). The release from the two omafilcon A lenses (SV and MF) was statistically similar to each other ( $p>0.05$, Tukey), while being different from all the other lens materials. Finally, etafilcon A, ocufilcon B and omafilcon B were all statistically different than all the other lens types ( $p>0.05$, post hoc Tukey). Analysis of release time showed no material demonstrating statistically significant changes in drug release between time points for $>1$ hour (etafilcon $\mathrm{A}$ ), with the majority released within the first 20 minutes.

\section{Release of atropine from contact lenses - I mg/mL loaded}

There was a statistically significant difference in the amount of atropine released from the different lens materials over time when loaded with $1 \mathrm{mg} / \mathrm{mL}$ atropine solutions $\left(F_{126,420}=6.46\right.$, $p<0.0001)$. Lenses made from the omafilcon A and B materials were statistically similar to each other $(p>0.05)$ and statistically different $(p<0.05)$ from all other lens types based on the post hoc Tukey's test. The release from narafilcon A, nelfilcon A (SV and MF) and comfilcon A (MF) was all statistically similar ( $p>0.05$, post hoc Tukey). Etafilcon A and ocufilcon $B$ lenses were statistically different from all the other lens types and each other ( $p<0.05$, post hoc Tukey). 
Table I Material properties of lenses used in this study

\begin{tabular}{|c|c|c|c|c|}
\hline Commercial name & $\begin{array}{l}\text { I-Day Acuvue } \\
\text { Moist }\end{array}$ & I-Day Acuvue TruEye & Biomedics I Day & Proclear I Day \\
\hline Manufacturer & Johnson \& Johnson & Johnson \& Johnson & CooperVision & CooperVision \\
\hline US adopted name & Etafilcon A & Narafilcon A & Ocufilcon B & Omafilcon A \\
\hline Water content (\%) & 58 & 46 & 58 & 60 \\
\hline $\begin{array}{l}\text { Center thickness } \\
\text { at }-3.00 \mathrm{D}(\mathrm{mm})\end{array}$ & 0.084 & 0.085 & 0.07 & 0.09 \\
\hline Oxygen permeability $\left(\times 10^{-11}\right)$ & 17 & 100 & 13 & 18 \\
\hline Oxygen transmissibility $\left(\times 10^{-9}\right)$ & 20 & 118 & 19 & 20 \\
\hline FDA group & IV & V & IV & II \\
\hline Principle monomers & $\mathrm{HEMA}+\mathrm{MA}+\mathrm{PVP}$ & $\begin{array}{l}\mathrm{mPDMS}+\mathrm{DMA}+\mathrm{HEMA}+ \\
\text { TEGDMA + PVP }\end{array}$ & $\mathrm{HEMA}+\mathrm{MA}$ & $\mathrm{HEMA}+\mathrm{PC}$ \\
\hline Multifocal design & - & - & - & - \\
\hline
\end{tabular}

Replacement frequency

Notes: For non-silicone hydrogels, oxygen permeability and transmissibility are calculated from the published water content and thickness values. For silicone hydrogels, values are reported from the manufacturer. ${ }^{44}$

Abbreviations: DMA, N,N-dimethylacrylamide; FDA, US Food and Drug administration; FM04I I M, $\alpha$-methacryloyloxyethyl iminocarboxyethyloxypropyl-poly(dimethylsiloxy)butyldimethylsilane; HEMA, poly-2-hydroxyethyl methacrylate; HOB, 2-hydroxybutyl methacrylate; IBM, isobornyl methacrylate; M3U, $\alpha \omega$-bis(methacryloyloxyethylimin ocarboxy ethyloxypropyl)-poly(dimethylsiloxane)-poly(trifluoropropylmethylsiloxane)-poly( $\omega$-methoxy-poly(ethyleneglycol)propyl methylsiloxane); MA, methacrylic acid; mPDMS, monofunctional polydimethylsiloxane; NVP, N-vinylpyrrolidone; PC, phosphorylcholine; PVA, polyvinyl alcohol partially acetalized with N-(formylmethyl)acrylamide; PVP, polyvinylpyrrolidone; TAIC, I,3,5-Triallyl-I,3,5-triazine-2,4,6(IH,3H,5H)-trione; TEGDMA, tetraethyleneglycol dimethacrylate; VMA, $N$-Vinyl- $N$-methylacetamide.

Analysis of release time showed no lens showing statistically significant changes in drug release between time points for $>1$ hour (ocufilcon $\mathrm{B}$ ), with the majority releasing within the first 30 minutes (Figure 2).

\section{Release of pirenzepine from contact lenses - $10 \mathrm{mg} / \mathrm{mL}$ loaded}

When loaded with $10 \mathrm{mg} / \mathrm{mL}$ of pirenzepine, there was a statistically significant difference between the amount of drug released over time between the different materials $\left(F_{126,420}=43.569, p<0.0001\right)$. Post hoc analysis suggested that the release of pirenzepine from nelfilcon $\mathrm{A}(\mathrm{SV}$ and $\mathrm{MF}$ ), and comfilcon A (MF) was all statistically similar $(p>0.05$, post hoc Tukey), while narafilcon A and delefilcon were statistically different compared to all other lens types. The lenses made from omafilcon A (SV and MF) were not statistically different from each other ( $p>0.05$, post hoc Tukey). Etafilcon A and ocufilcon B were not statistically different from each other $(p>0.05)$ but were statistically different from all other lens types. Narafilcon A demonstrated a prolonged released time compared to the other lenses, with significant changes in concentration observed for up to 8 hours when

Table 2 Milligrams of drug released per lens into $4 \mathrm{~mL}$ of PBS after 24 hours

\begin{tabular}{|c|c|c|c|c|}
\hline \multirow[t]{2}{*}{ Lens material } & \multicolumn{4}{|c|}{ Milligrams of drug released (standard deviation) per loading solution } \\
\hline & $\begin{array}{l}10 \mathrm{mg} / \mathrm{mL} \\
\text { atropine }\end{array}$ & $\begin{array}{l}10 \mathrm{mg} / \mathrm{mL} \\
\text { pirenzepine }\end{array}$ & $\begin{array}{l}\mathrm{I} \mathrm{mg} / \mathrm{mL} \\
\text { atropine }\end{array}$ & $\begin{array}{l}\text { I mg/mL } \\
\text { pirenzepine }\end{array}$ \\
\hline Etafilcon A & $1.026(0.035)$ & $0.341(0.039)$ & $0.156(0.004)$ & $0.147(0.004)$ \\
\hline Ocufilcon B & $0.979(0.024)$ & $0.321(0.027)$ & $0.174(0.006)$ & $0.151(0.005)$ \\
\hline Omafilcon A (SV) & $0.575(0.031)$ & $0.536(0.033)$ & $0.104(0.006)$ & $0.091(0.004)$ \\
\hline Omafilcon A (MF) & $0.540(0.029)$ & $0.524(0.028)$ & $0.099(0.007)$ & $0.089(0.004)$ \\
\hline Omafilcon B (MF) & $0.840(0.013)$ & $0.631(0.026)$ & $0.110(0.003)$ & $0.125(0.008)$ \\
\hline Narafilcon A & $0.385(0.012)$ & $0.264(0.009)$ & $0.047(0.005)$ & $0.037(0.0002)$ \\
\hline Nelfilcon A (SV) & $0.310(0.021)$ & $0.294(0.009)$ & $0.027(0.003)$ & $0.047(0.013)$ \\
\hline Nelfilcon A (MF) & $0.328(0.019)$ & $0.280(0.024)$ & $0.038(0.007)$ & $0.044(0.004)$ \\
\hline Comfilcon A (MF) & $0.316(0.007)$ & $0.291(0.019)$ & $0.034(0.005)$ & $0.047(0.002)$ \\
\hline Delefilcon A & $0.266(0.013)$ & $0.200(0.006)$ & $0.052(0.014)$ & $0.026(0.001)$ \\
\hline
\end{tabular}

Note: SV and MF denote the single vision and multifocal variant of a particular lens material, respectively.

Abbreviation: PBS, phosphate-buffered saline. 


\begin{tabular}{|c|c|c|c|c|c|}
\hline Dailies Total One & Focus Dailies & $\begin{array}{l}\text { Focus Dailies } \\
\text { Progressive }\end{array}$ & Biofinity Multifocal & $\begin{array}{l}\text { Proclear I Day } \\
\text { Multifocal }\end{array}$ & Proclear Multifocal \\
\hline Alcon & Alcon & Alcon & CooperVision & CooperVision & CooperVision \\
\hline Delefilcon A & Nelfilcon A & Nelfilcon A & Comfilcon A & Omafilcon A & Omafilcon B \\
\hline 33 (>80 at surface) & 69 & 69 & 48 & 60 & 62 \\
\hline 0.09 & 0.10 & 0.11 & 0.08 & 0.09 & 0.16 \\
\hline 140 & 26 & 26 & 128 & 18 & 20 \\
\hline 156 & 26 & 24 & 160 & 20 & 12 \\
\hline V & II & II & $\mathrm{V}$ & II & II \\
\hline Unpublished & PVA & PVA & $\begin{array}{l}\mathrm{FM} 04 \mathrm{IIM}+\mathrm{HOB}+\mathrm{IBM}+\mathrm{M} 3 \mathrm{U}+ \\
\mathrm{NVP}+\mathrm{TAIC}+\mathrm{VMA}\end{array}$ & HEMA + PC & HEMA + PC \\
\hline- & - & $\begin{array}{l}\text { Progressive center } \\
\text { near/distance } \\
\text { surround }\end{array}$ & $\begin{array}{l}\mathrm{D} \text { and } \mathrm{N} \text { lenses, spherical } \\
\text { central and surround zones and } \\
\text { progressive intermediate between }\end{array}$ & $\begin{array}{l}\text { Aspherical, center } \\
\text { near, distance } \\
\text { surround }\end{array}$ & $\begin{array}{l}\mathrm{D} \text { and } \mathrm{N} \text { lenses, } \\
\text { spherical central } \\
\text { and surround zones } \\
\text { and progressive } \\
\text { intermediate between }\end{array}$ \\
\hline Daily & Daily & Daily & Monthly & Daily & Monthly \\
\hline
\end{tabular}

loaded with $10 \mathrm{mg} / \mathrm{mL}$ of pirenzepine (Figure 3), although it released the lowest amount of pirenzepine overall. All other lenses reached their plateau concentrations within 1 hour.

\section{Release of pirenzepine from contact lenses - I $\mathrm{mg} / \mathrm{mL}$ loaded}

There were statistically significant differences observed between the amount of pirenzepine released from the

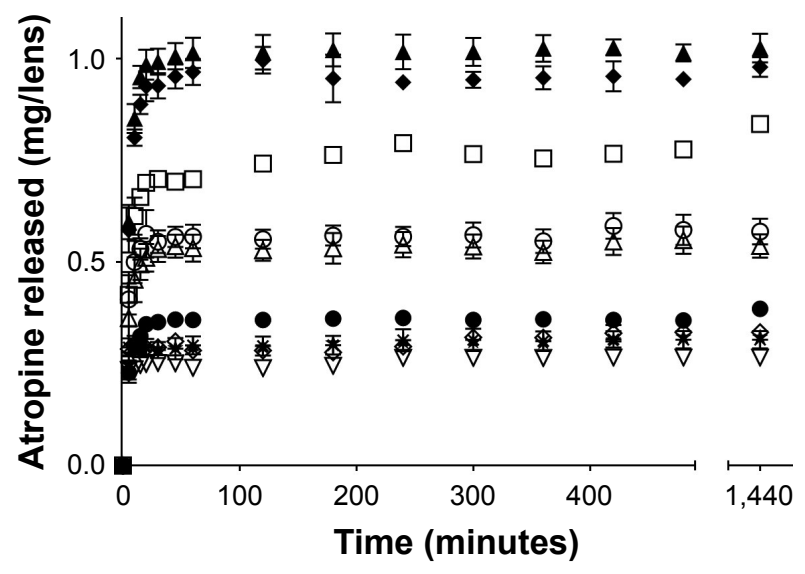

Figure I Atropine release over 24 hours in $4 \mathrm{~mL}$ of PBS from contact lenses after 24 hours of uptake in $10 \mathrm{mg} / \mathrm{mL}$ atropine solution.

Notes: Bars represent standard deviation. $\boldsymbol{\Delta}$, etafilcon $A ; \bullet$, ocufilcon $B ; \square$, omafilcon $B(M F)$; $O$, omafilcon $A(S V) ; \triangle$, omafilcon $A(M F) ; \bullet$, narafilcon $A$; $*$, nelfilcon A (SV); $\diamond$, nelfilcon A (MF); $\star$, comfilcon A (MF); $\nabla$, delefilcon $A$ ( $n=4 /$ material). SV and MF denote the single vision and multifocal variant of a particular lens material, respectively.

Abbreviation: PBS, phosphate-buffered saline. different materials over time after loading with $1 \mathrm{mg} / \mathrm{mL}$ pirenzepine solutions $\left(F_{126,420}=33.927, p<0.0001\right)$. When loaded with $1 \mathrm{mg} / \mathrm{mL}$ of pirenzepine, the release of pirenzepine from nelfilcon A (MF), nelfilcon A (SV) and comfilcon A (MF) was all statistically not different from each other ( $p>0.05$, post hoc Tukey), as were narafilcon $\mathrm{A}$ and delefilcon A from each other ( $p>0.05$, post hoc Tukey). Omafilcon A lenses (SV and MF) were not statistically

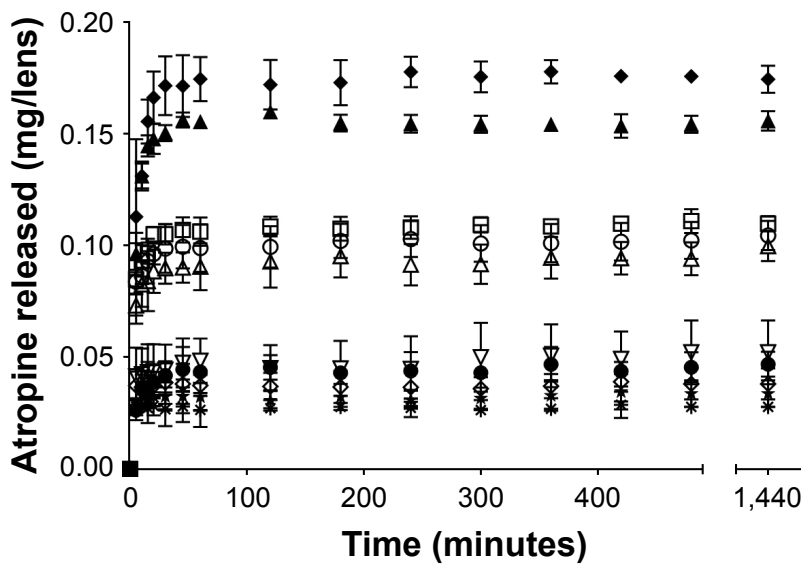

Figure 2 Atropine release over 24 hours in $4 \mathrm{~mL}$ of PBS from contact lenses after 24 hours of uptake in I mg/mL atropine solution.

Notes: Bars represent standard deviation. $\boldsymbol{\Delta}$, etafilcon $\mathrm{A} ; \bullet$, ocufilcon $\mathrm{B} ; \square$, omafilcon $B$ (MF); $O$, omafilcon $A(S V) ; \triangle$, omafilcon A (MF); $\bullet$, narafilcon $A$; $*$, nelfilcon A (SV); $\diamond$, nelfilcon A (MF); $\star$, comfilcon A (MF); $\nabla$, delefilcon $A(n=4 /$ material). SV and MF denote the single vision and multifocal variant of a particular lens material, respectively.

Abbreviation: PBS, phosphate-buffered saline. 


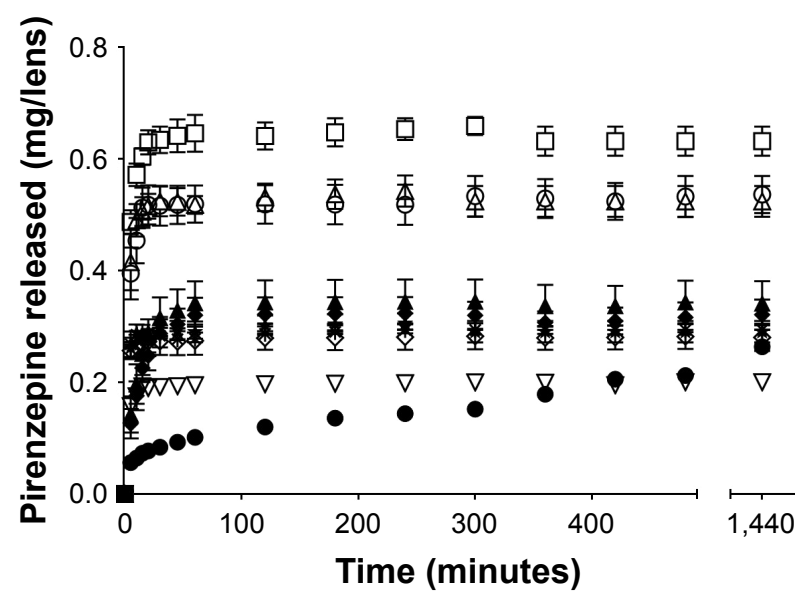

Figure 3 Pirenzepine release over 24 hours in $4 \mathrm{~mL}$ of PBS from contact lenses after 24 hours of uptake in $10 \mathrm{mg} / \mathrm{mL}$ pirenzepine solution.

Notes: Bars represent standard deviation. $\boldsymbol{\Delta}$, etafilcon $A$; $\diamond$, ocufilcon $B ; \square$, omafilcon $B(M F)$; $O$, omafilcon $A(S V) ; \triangle$, omafilcon $A(M F) ; \bullet$, narafilcon $A$; *, nelfilcon A (SV); $\diamond$, nelfilcon A (MF); $\star$, comfilcon A (MF); $\nabla$, delefilcon $A(n=4 /$ material). SV and MF denote the single vision and multifocal variant of a particular lens material, respectively.

Abbreviation: PBS, phosphate-buffered saline.

different from each other, although they were in this case different from omafilcon B. Etafilcon A and ocufilcon B were all statistically different from all the other lens types. Analysis of release time showed no lens showing statistically significant changes in drug release between time points for $>45$ minutes. The only exception was again the narafilcon A material, which according to analysis continued to release pirenzepine into the solution for 4 hours before no significant change in release concentration was observed (Figure 4).

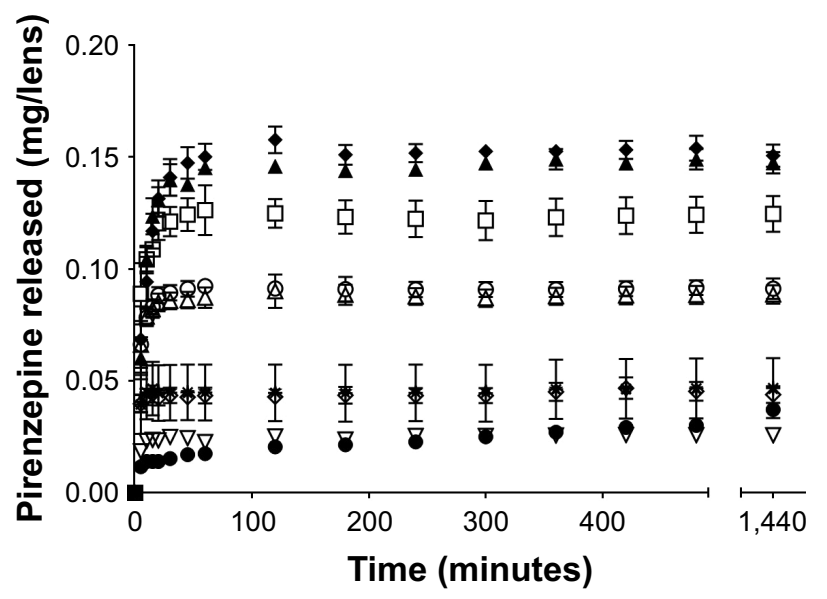

Figure 4 Pirenzepine release over 24 hours in $4 \mathrm{~mL}$ of PBS from contact lenses after 24 hours of uptake in $1 \mathrm{mg} / \mathrm{mL}$ pirenzepine solution.

Notes: Bars represent standard deviation. $\boldsymbol{\Delta}$, etafilcon $A$; $\bullet$, ocufilcon $B$; $\square$, omafilcon B (MF); O, omafilcon A (SV); $\triangle$, omafilcon A (MF); $\bullet$, narafilcon A; *, nelfilcon A (SV); $\diamond$, nelfilcon A (MF); $\star$, comfilcon A (MF); $\nabla$, delefilcon A ( $n=4 /$ material). SV and MF denote the single vision and multifocal variant of a particular lens material, respectively.

Abbreviation: PBS, phosphate-buffered saline.

\section{Discussion}

The use of contact lenses as an avenue to deliver drugs to the anterior surface of the eye has seen a resurgence of interest in the past 10 years, evidenced by an increase in the number of papers published investigating these applications. ${ }^{29,32-37}$ Commercially available lenses are an attractive initial target for research in this field, due to their availability to most eye care practitioners and their reproducibility from lens to lens, owing to large-scale manufacturing within a defined limit of acceptable commercial tolerances. . $^{27,29,32}$ The reproducibility between lenses and materials can be seen in this study through comparison of multifocal and non-multifocal release of drugs made from the same material. Examination of the amount of drug released by the single vision and progressive versions of the nelfilcon A material or from the daily and daily multifocal omafilcon A show statistically similar release profiles. In the majority of cases, the release curves are virtually identical. The implication is that the optical modification needed to add in the multifocal aspect of the lens design has only a negligible effect on the drug release kinetics, and the differences seen between lenses is more likely due to inherent material properties. Of interest is the comparison of lenses made from omafilcon A and B materials. While extremely similar to omafilcon A, the slight change in water content and center thickness allows for statistically significant differences in drug release from omafilcon B material in comparison to omafilcon A (SV) and omafilcon A (MF) materials when loaded with $10 \mathrm{mg} / \mathrm{mL}$ solutions of atropine and pirenzepine as well as $1 \mathrm{mg} / \mathrm{mL}$ of pirenzepine.

There were significant differences in the overall amount of drug that was released from these different materials after soaking in the same loading solutions for 24 hours. Other than one drug loading concentration ( $10 \mathrm{mg} / \mathrm{mL}$ of pirenzepine), the two materials, which were classified by the US Food and Drug Administration (FDA) Category IV [ $>50 \%$ water content, ionically charged surface], etafilcon A and ocufilcon B, released the greatest overall amount of the two drugs. This interaction between charged small molecules such as drugs and ionic lenses has previously been demonstrated in studies with other pharmaceuticals and commercial lenses, with the explanation that charged interactions between the materials and drugs allow for a greater amount of drug to be loaded and subsequently released..$^{27,31}$ The other material property of note is the performance of silicone hydrogel lenses, as they have previously been shown in studies investigating other drugs to have less drug release potential compared to non-silicone hydrogels. ${ }^{27-31}$ This was also observed in this study, with the narafilcon A and comfilcon A materials releasing some of the 
lowest amounts of drugs, regardless of drug type or loading concentration. Release kinetics from the narafilcon A material is interesting in that it was the only lens to demonstrate some aspect of extended release beyond 1 hour, with a statistically significant release being observed for periods of up to 8 hours. This is also one of the first studies to report on the release of pharmaceuticals from the delefilcon A material, which has been marketed by the manufacturer as a "hybrid" material, with a non-silicone-based outer shell to improve comfort and wettability and a central silicone core to allow for improved oxygen permeability. ${ }^{38}$ In this study, the delefilcon A material consistently released one of the least amounts of each drug and did so in an extremely fast manner, rendering it unlikely to be a suitable candidate for sustained drug release without some sort of purposeful modification.

There are several examples within the literature of commercial contact lenses being investigated for their drug release properties. Comparison of the present results with studies investigating dexamethasone sodium phosphate release from lenses is illustrative, considering that a similar drug loading concentration was used $(0.1 \%$ or $1 \mathrm{mg} / \mathrm{mL}) .{ }^{30}$ In the previous study, the investigated contact lenses released between 20 and $30 \mu \mathrm{g}$ of dexamethasone/lens, with the one outlier being the lens formed from the high water content alphafilcon A material, which released upward of $60 \mu \mathrm{g} /$ lens. ${ }^{30}$ Lenses in this study loaded with similar concentrations of atropine and pirenzepine released significantly more of each of the drugs, ranging from $25 \mu \mathrm{g} / \mathrm{lens}$ to $>150 \mu \mathrm{g} / \mathrm{lens}$ of atropine or pirenzepine released at the extremes. Etafilcon A and comfilcon A materials were utilized in both studies, and both pirenzepine and atropine demonstrated an increased release from these two materials compared to dexamethasone, possibly due to the differences in molecular weight, polarity and size between the drug molecules, with the molecular weight of dexamethasone being 516.405 in comparison to 289.37 and 351.40 for atropine and pirenzepine, respectively. ${ }^{30}$ Other studies utilized different loading concentrations and $\mathrm{pH}$ in preparation of solutions of charged drug molecules. In the example of ciprofloxacin hydrochloride, the zwitterionic nature of the drug at physiological $\mathrm{pH}$ causes poor aqueous solubility and thus a $\mathrm{pH} 4$ loading solution is used to allow for a commercially viable $3 \mathrm{mg} / \mathrm{mL}$ uptake solution to be formed. ${ }^{27}$ The highly charged nature of the ciprofloxacin molecules at this $\mathrm{pH}$ allows for large amounts of the drug to be loaded and released from lenses with charged surfaces. Etafilcon A demonstrated a significant ciprofloxacin release, more than the amount of atropine or pirenzepine released when loaded with $1 \mathrm{mg} / \mathrm{mL}$ solutions, although it was ultimately less when the loading concentration of the two drugs was increased to $10 \mathrm{mg} / \mathrm{mL} .{ }^{27}$ Ketotifen fumarate, an anti-allergy drug, has also been investigated for its uptake and release properties from commercial contact lenses. ${ }^{31}$ The study utilized a low loading concentration of only $0.25 \mathrm{mg} / \mathrm{mL}$ to match the drug concentrations commonly found in commercially available eye drops, and the amount of ketotifen released ranged from 11 to $28 \mathrm{mg} / \mathrm{lens} .{ }^{31}$ The study is also notable for investigations into the effect of variation of the loading concentration over a 25 -fold range $(0.05-1.25 \mathrm{mg} / \mathrm{mL})$ for one of the study lenses (ocufilcon B), where similar to this study, it was demonstrated that while increasing the concentration of the loading solution increased the amount of drug released overall, the amount of drug released is less than what would be expected simply from the factor increase in the loading concentration. This, combined with the currently presented results, suggests that there are diminishing returns in the amount of drug that can be effectively loaded into these lenses for release by increasing the loading concentration. ${ }^{31}$ In almost all cases, the overall trend in terms of release time is also similar across the different drugs and different lens types, with the majority of the lenses reaching a plateau concentration within the release solution in $<1$ hour, with the rare exceptions of drug-commercial lens combinations releasing for $>2-3$ hours. ${ }^{27,30,31}$

The limitation of commercial lenses to sustain drug release when investigated in vitro has led many researchers within this field to investigate methods to extend drug release, including techniques such as applying Vitamin E coatings, incorporating liposomes and molecular imprinting. ${ }^{39-41}$ A recent study has investigated the incorporation of atropine into the process of silicone hydrogel synthesis. In these experimental materials, although a similar burst release is observed in that a majority of the drug release was seen in an initial time period, this is achieved over the course of $2-4$ days, with upward of 14 days of continuous release deemed possible. ${ }^{42}$ There is still potential utility for unmodified commercial lenses to deliver drugs for diseases or conditions where the dose of drug delivered is of greater importance than the release kinetics. In conditions such as ocular allergy, a single daily dose of a topically prescribed agent is generally all that is required, and thus, a lens that releases this dose while also correcting for refractive error may be useful in aiding patient compliance. ${ }^{31}$ The use of commercially available lenses in a daily disposable context for drug delivery would have the added advantages of decreased risk of adverse events due to lack of overnight contact lens wear and consistent dosages as 
a new drug-loaded lens is given on a daily basis. Considering the success of once a day dosing in the pharmaceutical myopia trials, this type of dosage modality using a commercial lens may be viable..$^{13,14}$

The two drugs used in this study were atropine sulfate and pirenzepine dihydrochloride, which were chosen due to evidence of their effectiveness at slowing the progression of myopia. ${ }^{13,14,18-20}$ The two concentrations of the drug in this study $(10 \mathrm{mg} / \mathrm{mL}$ or $1 \%$ and $1 \mathrm{mg} / \mathrm{mL}$ or $0.1 \%)$ were chosen because of the commercial availability of atropine ( $1 \%)$ and the evidence that lower concentrations $(0.5 \%, 0.1 \%$ and $0.01 \%$ ) of the drugs may still be effective in preventing myopia progression. ${ }^{14,43}$ Lower concentrations of atropine still being effective in controlling myopia progression is an important finding as it is now possible to utilize the drugs to effectively limit myopia progression, while simultaneously mitigating the functional side effects of the anti-muscarinic agents such as prolonged pupillary mydriasis, decreased visual acuity and accommodative paralysis. ${ }^{14}$ Based on a typical eye drop size of $50 \mu \mathrm{L}$, the amount of drug instilled on to the ocular surface is $0.5,0.05$ and $0.005 \mathrm{mg}$ for $1 \%$, $0.1 \%$ and $0.01 \%$ solutions, amounts that are easily achieved in the $2 \mathrm{~mL}$ release system by some of the lenses loaded with $10 \mathrm{mg} / \mathrm{mL}$ or $1 \mathrm{mg} / \mathrm{mL}$ of the two drugs.

No single method of myopia control has been demonstrated to be completely effective in preventing myopic eye growth. This study provides insight into the different loading and release properties of the different commercial contact lens materials, allowing for further investigation into a potential combined optical and pharmaceutical myopia treatment system. However, it remains unknown whether the combination of these two particular types of myopia control has an additive or synergistic effect or an antagonistic and detrimental effect on each other in their ability to control eye growth, and it requires further investigation to determine the long-term potential of combining these two techniques.

\section{Conclusion}

In this study, several daily disposable and multifocal contact lenses were investigated for their potential to release two anti-myopia drugs. All lenses showed some degree of drug release when monitored in vitro, although the majority released the drugs in an uncontrolled manner. Given that no single method investigated thus far has been successful in completely preventing myopia progression, a combination of pharmaceutical and optical treatment techniques may be a viable future avenue, and a contact lens-based drug delivery system is an option worthy of further evaluation.

\section{Acknowledgment}

This study was supported by the NSERC 20/20 Network for the development of advanced ophthalmic materials.

\section{Disclosure}

The authors report no conflicts of interest and have no proprietary interest in any of the materials mentioned in this article.

\section{References}

1. Lin LL-K, Shih Y-F, Tsai C-B, et al. Epidemiologic study of ocular refraction among schoolchildren in Taiwan in 1995. Optom Vis Sci. 1999;76(5):275-281.

2. Jung SK, Lee JH, Kakizaki H, Jee D. Prevalence of myopia and its association with body stature and educational level in 19-year-old male conscripts in Seoul, South Korea. Invest Ophthalmol Vis Sci. 2012; 53(9):5579-5583.

3. Sun J, Zhou J, Zhao P, et al. High prevalence of myopia and high myopia in 5060 Chinese university students in Shanghai. Invest Ophthalmol Vis Sci. 2012;53(12):7504-7509.

4. Koh V, Yang A, Saw SM, et al. Differences in prevalence of refractive errors in young Asian males in Singapore between 1996-1997 and 2009-2010. Ophthalmic Epidemiol. 2014;21(4):247-255.

5. Holden B, Sankaridurg P, Smith E, Aller T, Jong M, He M. Myopia, an underrated global challenge to vision: where the current data takes us on myopia control. Eye (Lond). 2014;28(2):142-146.

6. Sherwin JC, Mackey DA. Update on the epidemiology and genetics of myopic refractive error. Expert Rev Ophthalmol. 2013;8(1):63-87.

7. Morgan IG, Ohno-Matsui K, Saw SM. Myopia. Lancet. 2012;379(9827): 1739-1748.

8. Leo SW, Young TL. An evidence-based update on myopia and interventions to retard its progression. J AAPOS. 2011;15(2):181-189.

9. Jones D, Luensmann D. The prevalence and impact of high myopia. Eye Contact Lens. 2012;38(3):188-196.

10. Walline JJ, Greiner KL, McVey ME, Jones-Jordan LA. Multifocal contact lens myopia control. Optom Vis Sci. 2013;90(11):1207-1214.

11. Cooper J, Schulman E, Jamal N. Current status on the development and treatment of myopia. Optometry. 2012;83(5):179-199.

12. Gwiazda J. Treatment options for myopia. Optom Vis Sci. 2009; 86(6):624-628.

13. Chua WH, Balakrishnan V, Chan YH, et al. Atropine for the treatment of childhood myopia. Ophthalmology. 2006;113(12):2285-2291.

14. Chia A, Chua WH, Cheung YB, et al. Atropine for the treatment of childhood myopia: safety and efficacy of $0.5 \%, 0.1 \%$, and $0.01 \%$ doses (atropine for the treatment of myopia 2). Ophthalmology. 2012; 119(2):347-354.

15. Cooper J, Eisenberg N, Schulman E, Wang FM. Maximum atropine dose without clinical signs or symptoms. Optom Vis Sci. 2013;90(12): 1467-1472.

16. Chia A, Lu QS, Tan D. Five-year clinical trial on atropine for the treatment of myopia 2 myopia control with atropine $0.01 \%$ eyedrops. Ophthalmology. 2016;123(2):391-399.

17. Bartlett JD, Niemann K, Houde B, Allred T, Edmondson MJ, Crockett RS. A tolerability study of pirenzepine ophthalmic gel in myopic children. J Ocul Pharmacol Ther. 2003;19(3):271-279.

18. Siatkowski RM, Cotter S, Miller JM, et al; US Pirenzepine Study Group. Safety and efficacy of $2 \%$ pirenzepine ophthalmic gel in children with myopia: a 1-year, multicenter, double-masked, placebo-controlled parallel study. Arch Ophthalmol. 2004;122(11):1667-1674.

19. Siatkowski RM, Cotter SA, Crockett RS, et al; U.S. Pirenzepine Study Group. Two-year multicenter, randomized, double-masked, placebocontrolled, parallel safety and efficacy study of $2 \%$ pirenzepine ophthalmic gel in children with myopia. J AAPOS. 2008;12(4):332-339. 
20. Tan DT, Lam DS, Chua WH, Shu-Ping DF, Crockett RS; Asian Pirenzepine Study Group. One-year multicenter, double-masked, placebocontrolled, parallel safety and efficacy study of $2 \%$ pirenzepine ophthalmic gel in children with myopia. Ophthalmology. 2005;112(1):84-91.

21. White CJ, Byrne ME. Molecularly imprinted therapeutic contact lenses. Expert Opin Drug Deliv. 2010;7(6):765.

22. Sedlácek J. Possibility of the application of ophthalmic drugs with the use of gel contact lenses. Cesk Oftalmol. 1965;21(6):509-512.

23. Wichterle O, Lim D, inventors; Method for producing shaped articles from three-dimensional hydrophilic polymers. United States patent US2976576 A. 1961 March 28.

24. Nordstrom BL, Friedman DS, Mozaffari E, Quigley HA, Walker AM. Persistence and adherence with topical glaucoma therapy. Am J Ophthalmol. 2005;140(4):598-606.

25. Walline JJ, Jones LA, Sinnott L, et al. Randomized trial of the effect of contact lens wear on self-perception in children. Optom Vis Sci. 2009 86(3):222-232.

26. Rah MJ, Walline JJ, Jones-Jordan LA, et al. Vision specific quality of life of pediatric contact lens wearers. Optom Vis Sci. 2010;87(8) 560-566.

27. Hui A, Boone A, Jones L. Uptake and release of ciprofloxacin- $\mathrm{HCl}$ from conventional and silicone hydrogel contact lens materials. Eye Contact Lens. 2008;34(5):266.

28. Phan CM, Subbaraman LN, Jones L. In vitro uptake and release of natamycin from conventional and silicone hydrogel contact lens materials. Eye Contact Lens. 2013;39(2):162-168.

29. Karlgard C, Jones L, Moresoli C. Uptake and release of Acular from silicone-hydrogel and conventional hydrogel contact lens materials. Optom Vis Sci. 2000;77(12s):179.

30. Boone A, Hui A, Jones L. Uptake and release of dexamethasone phosphate from silicone hydrogel and group I, II, and IV hydrogel contact lenses. Eye Contact Lens. 2009;35(5):260.

31. Soluri A, Hui A, Jones L. Delivery of ketotifen fumarate by commercial contact lens materials. Optom Vis Sci. 2012;89(8):1140-1149.

32. Karlgard C, Jones L, Moresoli C. Uptake and release of ciloxan from silicone-hydrogel and conventional hydrogel contact lens materials. Invest Ophthalmol Vis Sci. 2001;42(4):s592.
33. Alvarez-Lorenzo C, Hiratani H, Gómez-Amoza JL, Martínez-Pacheco R, Souto C, Concheiro A. Soft contact lenses capable of sustained delivery of timolol. J Pharm Sci. 2002;91(10):2182.

34. Byrne ME, Park K, Peppas NA. Molecular imprinting within hydrogels. Adv Drug Deliv Rev. 2002;54(1):149.

35. Hiratani H, Alvarez-Lorenzo C. Timolol uptake and release by imprinted soft contact lenses made of N,N-diethylacrylamide and methacrylic acid. J Control Release. 2002;83(2):223.

36. Karlgard CC, Wong NS, Jones LW, Moresoli C. In vitro uptake and release studies of ocular pharmaceutical agents by silicon-containing and p-HEMA hydrogel contact lens materials. Int J Pharm. 2003; 257(1-2):141-151.

37. Hiratani H, Mizutani Y, Alvarez-Lorenzo C. Controlling drug release from imprinted hydrogels by modifying the characteristics of the imprinted cavities. Macromol Biosci. 2005;5(8):728.

38. Pruitt J, Bauman E. The development of dailies Total 1 water gradient contact lenses. Optometric Management. 2013:40-44.

39. Hui A, Willcox M, Jones L. In vitro and in vivo evaluation of novel ciprofloxacin-releasing silicone hydrogel contact lenses. Invest Ophthalmol Vis Sci. 2014;55(8):4896-4904.

40. Peng CC, Ben-Shlomo A, MacKay EO, Plummer CE, Chauhan A. Drug delivery by contact lens in spontaneously glaucomatous dogs. Curr Eye Res. 2012;37(3):204-211.

41. Danion A, Arsenault I, Vermette P. Antibacterial activity of contact lenses bearing surface-immobilized layers of intact liposomes loaded with levofloxacin. J Pharm Sci. 2007;96(9):2350-2363.

42. Lasowski F, Sheardown H. Atropine and roscovitine release from model silicone hydrogels. Optom Vis Sci. 2016;93(4):404-411.

43. Chia A, Chua WH, Wen L, Fong A, Goon YY, Tan D. Atropine for the treatment of childhood myopia: changes after stopping atropine $0.01 \%$, 0.1\% and 0.5\%. Am J Ophthalmol. 2014;157(2):451-457.e1.

44. Morgan PB, Efron N. The oxygen performance of contemporary hydrogel contact lenses. Cont Lens Anterior Eye. 1998;21(1):3-6.
Clinical Ophthalmology

\section{Publish your work in this journal}

Clinical Ophthalmology is an international, peer-reviewed journal covering all subspecialties within ophthalmology. Key topics include: Optometry; Visual science; Pharmacology and drug therapy in eye diseases; Basic Sciences; Primary and Secondary eye care; Patient Safety and Quality of Care Improvements. This journal is indexed on

\section{Dovepress}

PubMed Central and CAS, and is the official journal of The Society of Clinical Ophthalmology (SCO). The manuscript management system is completely online and includes a very quick and fair peer-review system, which is all easy to use. Visit http://www.dovepress.com/ testimonials.php to read real quotes from published authors. 